\title{
Novel Farming Innovation for High Production of Black Pepper (Piper nigrum L.) Planting Materials
}

\author{
Kho Pei Ee and Chen Yi Shang \\ Malaysian Pepper Board, Jalan Utama, Pending Industrial Area, P.O. Box 1653, Kuching, Sarawak 93916, Malaysia
}

\begin{abstract}
In accordance to National Commodity Policy (2011-2020), Malaysian government targets at expending the pepper cultivated area from the current 16,331 ha to 20,110 ha by year 2020 . Based on a planting density of 2,000 vines/ha, there will be an urgent need of 7.588 million cuttings for the next five years in order to achieve this target. However, shortages of planting materials, low productivity and occurrence of pests and diseases remain as the major challenge of pepper industry nowadays. Therefore, a novel farming innovation, namely W-configuration cultivation method has been developed to ensure high production of planting materials for large-scale pepper cultivation and at the same time to maximize land use in pepper farm. A field evaluation was conducted to compare the cutting production among W-configuration, V-configuration and traditional cultivation method. W-configuration recorded the highest mean number of pepper cuttings produced with 11.97 cuttings per vine in every pruning cycle, or equivalent to $71 \%$ of increment as compared to 7.00 cuttings per vine produced from the traditional planting method. Meanwhile, V-configuration produced 8.91 of mean cuttings, which are significantly lower than those produced by W-configuration method and yet comparable to traditional method. Based on return on investment (ROI) analysis, implementation of W-configuration cultivation method was able to achieve $35 \%$ of return per cycle of planting within two years for the first cycle and upsurged to approximately $355 \%$ for the subsequence cycle. Furthermore, this novel innovation also out-yielded traditional planting method by $75.27 \%$ for the first and second year of green berry production. The ROI analysis proved the feasibility of this newly developed cultivation method to create potential new income for pepper smallholders in Malaysia, who traditionally cultivate pepper for its peppercorn production. This study also enlightened the thorough planting procedures of W-configuration cultivation method mainly for pepper cutting production.
\end{abstract}

Key words: Black pepper, W-configuration, pepper cuttings, return on investment.

\section{Introduction}

Piper nigrum L., commonly known as black pepper, is a perennial woody vine belonging to Piperaceae family. The plant is primarily cultivated for its fruits, which is widely used as spice in culinary preparation, food flavoring, seasoning and perfumery, and as a condiment throughout the world [1]. It has gained a global recognition as the "king of spice" due to its monetary value and trade in the international spice market [2]. In Malaysia, particularly in the state of Sarawak, black pepper has played pivotal role as cash crop for farmers [3].

According to the International Pepper Community (IPC) (2014), Malaysia has the distinction of being the

Corresponding author: Kho Pei Ee, M.Sc., research fields: plant agronomy and plant biotechnology. world's 5th largest pepper producer country with an output of 20,500 tons and total export of 13,429 tons, which worth RM 285.27 million in 2014. In addition, domestic consumption of pepper shot up by $11 \%$ to 13,500 tons in 2015, compared to 12,000 tons in 2014 . Pepper planting was a lucrative endeavor and the demand on food and non-food pepper based products is expected to increase in future. Consequently, a constant supply of planting materials is essential for sustaining and boosting up the pepper productivity of the nation.

Black pepper can be propagated vegetatively, as well as through seeds. However, seed propagation is cumbersome, uncertain and yields only a few heterogeneous progenies due to their short viability and high sterility in post-fertilization stages [4]. Apart from this, plants raise in this way, of necessity from 
different vines, show variations in growth habit and productivity [1]. Hence, vegetative propagation is preferred for commercial cultivation. Though black pepper can be propagated through cuttings, grafting, layering and budding, rooted cuttings are preferred for commercial cultivation $[5,6]$.

Pepper plant produces two types of branches. The straight, upward growing, orthotropic, monopodial with adventitious roots at each node clinging on the support is called orthotropic branch, orthotropic stem, orthotropic shoot or the terminal. The other is the lateral growing, sympodial, plagiotropic branch with inflorescence and fruit spike at node, which is known as plagiotropic branch, lateral branch or the lateral [4, $7,8]$. Besides these two types of branches, the pepper plant also produces stolons or adventitious ground runner shoots emerged from the base of the pepper vines, which has long been used as planting material in India, Indonesia, Sri Lanka, Vietnam and many other pepper producing countries [9].

Unlike many pepper producer countries, the planting materials for pepper cultivation are pepper cuttings, which sourced from the orthotropic branch (terminal shoot) of a healthy and vigorously growing young vine with varying number of nodes [7]. Currently, the five-node cutting with two healthy lateral branches arising from the top two nodes is recommended for planting [10], whilst, at time of planting material shortage, four-node cutting can also be used [7]. First round of pruning is normally carried out at six months after planting and subsequent pruning at four-month intervals. Under the traditional practice, a vine normally produces about 7-10 five-node cuttings and another 16-22 five-node cuttings for its first and second years after planting, respectively [7].

Annual planting material requirement for commercial cultivation of pepper in major producing countries exceeds several millions. The traditional planting method is relatively slow and is unable to sustain the constant supply of planting materials. In order to overcome this limitation, few rapid multiplication methods were developed in Sri Lanka, such as bamboo split method, which became increasingly popular in India [11], heap method (soil mound) and polythene tube method [9]. Besides, serpentine method and vertical column method have also been developed in India for the production of rooted cuttings $[9,12]$.

Feasible and rapid multiplication method for production of pepper planting materials has never been reported in Malaysia. Therefore, innovation on farming method to ensure efficient production of quality planting materials is necessary. Thus, this study was carried out to reveal the feasibility and practicability of $\mathrm{W}$-configuration and $\mathrm{V}$-configuration cultivation methods with focus on pepper cuttings production and yield performance. The thorough planting procedures of both cultivation methods elucidated in this study served as a useful guideline for production of quality pepper planting materials in order to sustain the productivity of pepper industry.

\section{Materials and Methods}

\subsection{Materials}

The used planting materials in this project were five-node cuttings, which were obtained from the terminal shoot of young pepper vines with the age of about 1-2 years old. To achieve high survival rate, pepper cuttings were rooted for up to two months at sand bin before transplanting to the field. In order to ensure the homogeneity of the experiment plot, only cultivar Semongok Aman was used in the current study. Whilst, belian (Eusideroxylon zwageri) posts with the suggested size of $5 \mathrm{~cm}$ in diameter and $2 \mathrm{~m}$ in height were used as pepper vine support as recommended in traditional planting method.

\subsection{Plot Establishment}

An experimental plot located at Sri Aman, Sarawak, Malaysia was initiated to evaluate the production of pepper cuttings for the first two years and thereafter for the yield performance. The plot was planted with 
approximately 315 vines of two-year old cultivar Semongok Aman plants and was arranged in a completely randomized design (CRD) with three cultivation methods, namely (1) W-configuration; (2) V-configuration; (3) single-post or normal planting method with traditional good agricultural practice (GAP), which served as control for the experiment. All of the treatments were replicated three times with a total of 27 plants per treatment. Water shoots or stolon, which emerged at the basal part of main cuttings, was trained to the side posts at an angle of approximately $45^{\circ}$ with respect to the main posts and $60^{\circ}$ from the ground for W-configuration and $\mathrm{V}$-configuration cultivation method, respectively.

For all of the treatments conducted, three terminal shoots were trained on each post. Monitoring was carried out bimonthly, and subsequent pruning was conducted at four-month intervals. For the first two years, the data on production of pepper cuttings were recorded after every pruning. Whilst, assessment on yield performance for each treatment was carried out during the harvesting season by recording the average weight of green berries produced per vine for the subsequent year.

\subsection{Experimental Design}

The production of pepper cutting and green berry yield performance was statistically analyzed using one-way analysis of variance (ANOVA) by SPSS statistic version 16.0 (SPSS Inc., Chicago, IL). The differences among treatments were tested using Duncan's multiple range test (DMRT) at $p \leq 0.05$.

\subsection{Return on Investment (ROI) Analysis}

The analysis takes into account the pepper cuttings production per cycle (two years) in 1 ha of planting area, with a planting density of 2,000 vines/ha. The parameters of investment cost mainly are made up of non-factor cost, which consist of pepper posts $(E$. zwageri post), pepper cuttings, fertilizers, dolomite, weedicide, pesticide and miscellaneous farm implements, whilst, labor cost is considered as factor cost. The gross revenue is solely depending on the cuttings production. All of the statistical data were sourced from Division of Production \& Entrepreneurs Farmers Development, Malaysian Pepper Board. The standard market price for fresh cutting or un-rooted cutting is currently RM 3.00 per cutting and the ROI is calculated based on Eq. (1):

$$
\mathrm{ROI}=\frac{(\text { Gain from investment }- \text { Cost of investment })}{\text { Cost of investment }}
$$

\section{Results and Discussion}

\subsection{Farming Innovation}

Traditional cultivation practice (Fig. 1a) in Malaysia is to train a five-node cutting onto a post with three lower nodes being buried in the soil at an angle of $20^{\circ}$ to $35^{\circ}$, while the 4 th node is level with the ground surface. The 5 th node is above ground and placed close to the support. All cuttings are advisable to orientate in one direction to ease the fertilizer application. The newly developed terminal shoots are trained on the support by tying at a point just below each node to the support with fiber of plant origin, such as raffia or strings removed from a jute sack (gunny sack). To ensure good development of adventitious roots, every node is to be tied properly to the support [10]. The 1st harvest of cuttings is normally carried out by the time that vine has reached six months old. As a result of cutting harvest, the terminal shoot is pruned back to about $0.5 \mathrm{~m}$ from the mound. However, three new terminal shoots, which originate from the axillary buds, are allowed to develop [13]. Structural design of traditional, V-configuration and W-configuration cultivation methods were shown in Fig. 1.

Unlike the traditional cultivation method, V-configuration method (Fig. 1e) was designed with two posts in single planting point. The two posts of 2 $\mathrm{m}$ height were positioned in $60^{\circ}$ angle from the ground (Fig. 1f). Despite two posts, only one cutting is needed because the terminal shoots that proliferated 
from the single cutting will be trained to both posts. However, the practice of maintaining the vine is similar to the traditional method. W-configuration cultivation method (Fig. 1i) utilized three wooden posts of $2 \mathrm{~m}$ height, which positioned in W-configuration, with one intermediate post set up-righted and the other two lateral posts positioned $45^{\circ}$ each from the ground (Fig. $1 \mathrm{j}$ ). The essence of this farming innovation is the use of only one pepper cutting for each planting point with three posts. In this newly developed farming structure, three posts were used per planting point. For the up-righted intermediate post, the pepper shoot was trained similarly to the traditional planting, by the use of three terminal shoots. Whilst, stolon, or locally known as water shoot, which emerged from the main vine, was trained on the two lateral posts. Before this, stolon (water shoot, hanging shoot or runner shoot) has never been used as planting material in Malaysia due to unpromising growth and that it normally retarded before maturity. Therefore, stolon that is hanging or trailing on the ground is normally removed once emerged to reduce fertilizer uptake [3].
The breakthrough of W-configuration method is particularly on discovering the potential of stolon (Fig. 2a) as growing point. The stolon was found to be able to achieve excellence growth performance, which is comparable to the terminal shoot with the condition that the nodal part of stolon must be buried on the ground with top soil (Fig. 2b) prior to be trained on the lateral posts (Figs. 2c and 2d). The prerequisites to achieve this are that the stolon must emerge from the basal of vigorous growing vine and the nodal region is still viable. This treatment would promote the growth of adventitious roots on the buried node and eventually shoot growth. The stolon is ready for cuttings production approximately after six months trained on the two lateral posts. In line with the current finding, stolon is extensively used in India and Sri Lanka as planting materials for clonal propagation $[8,14]$. Furthermore, the viability of vine performance via runner shoots as planting material has proven by agronomists from India [12] and Indonesia [15].

\subsection{Pepper Cuttings Production}

The mean number of five-node pepper cutting per

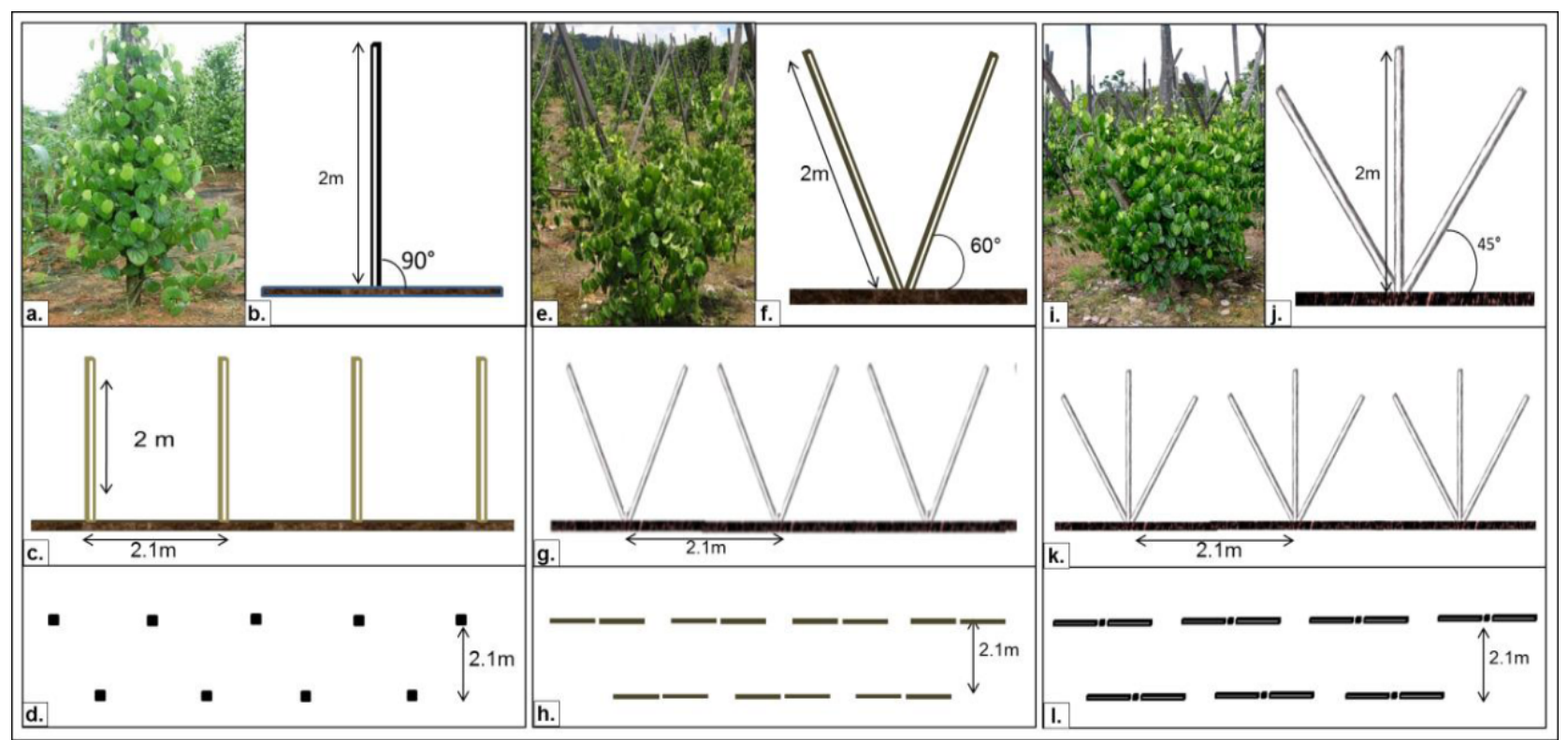

Fig. 1 Structural design of three cultivation methods.

(a) and (b) post arrangement; (c) horizontal view of pepper vine in single row; (d) aerial view of two row pepper vines for traditional cultivation method; (e) and (f) post arrangement; (g) horizontal view of pepper vine in single row; (h) aerial view of two row pepper vines for V-configuration cultivation method; (i) and (j) post arrangement; (k) horizontal view of pepper vine in single row; (l) aerial view of two row pepper vines for $\mathrm{W}$-configuration cultivation method. 


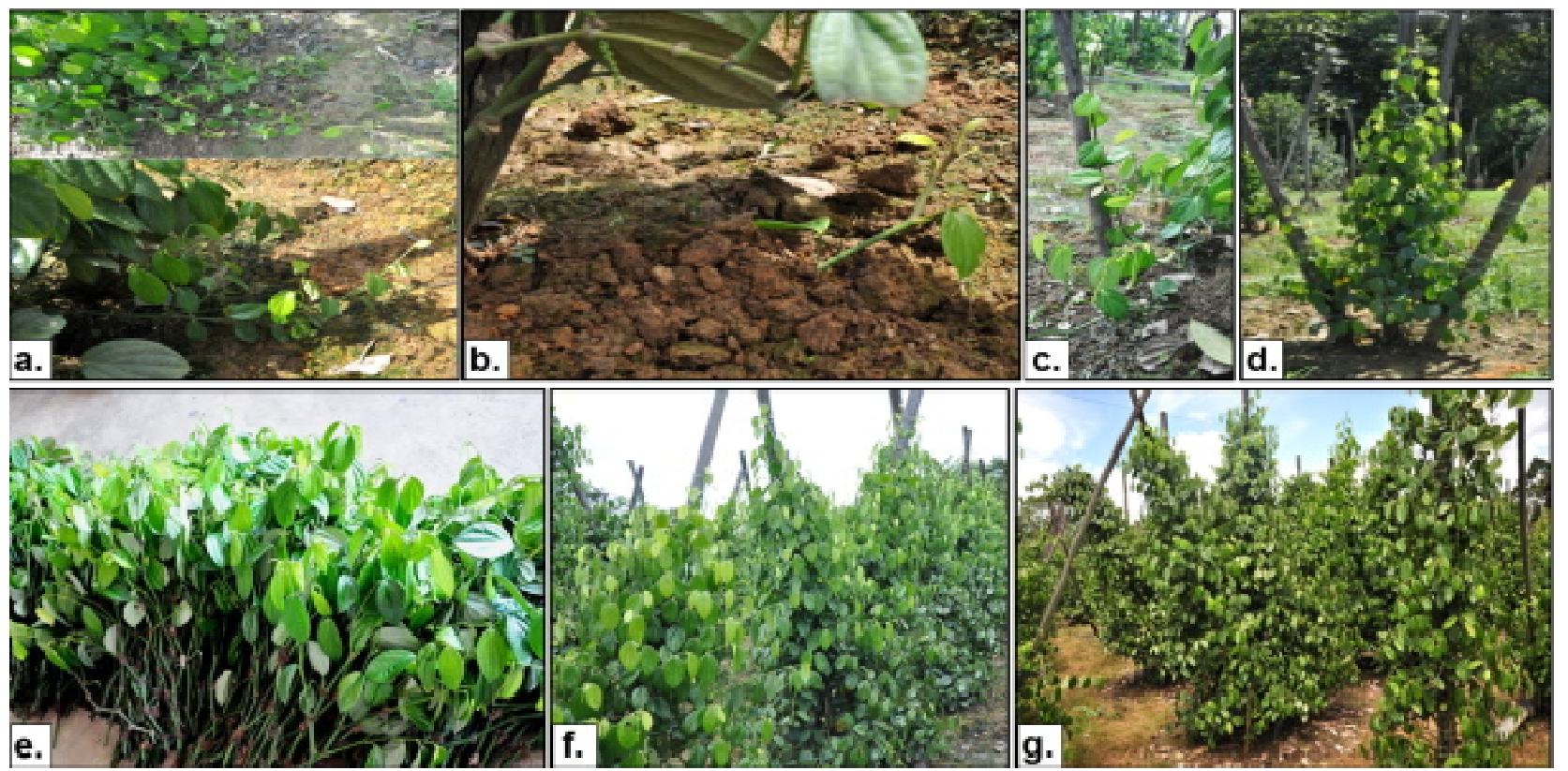

Fig. 2 (a) Runner shoots on the soil, (b) closer view of runner shoot buried with top soil at nodal part, (c) and (d) runner was tied and trained on belian post, (e) five-node pepper cuttings obtained after pruning, mature pepper vine on V-configuration (f) and W-configuration (g).

vine for the four rounds of pruning was presented in Table 1. Cuttings produced from W-configuration, V-configuration and traditional cultivation method were 12.04, 10.21 and 9.75 per vine, respectively, which indicated that no significant differences were among cultivation methods for the $1 \mathrm{st}$ round of pruning. This would be attributed to that the majority of pepper cuttings were produced from the terminal shoots, which were trained on the main post of the three cultivation methods. While, water shoots, which cling onto the side post, are just about to initiate some new terminal shoots during the 1 st round of pruning.

The number of five-node pepper cutting per vine produced by W-configuration (Fig. 2e) varied significantly among the three cultivation methods for the $2 \mathrm{nd}$, 3rd and 4 th rounds of pruning. Whilst, pepper cuttings produced from V-configuration only showed significant difference from other cultivation methods for the 2nd round of pruning, but no significant difference was observed as compared to the traditional method for the $3 \mathrm{rd}$ and 4 th rounds of pruning. $\mathrm{W}$-configuration recorded the significantly highest mean number of cuttings produced with 11.97 cutting per vine or equivalent to $71 \%$ of increment as compared to 7.00 cuttings per vine produced from traditional cultivation method. Meanwhile, V-configuration produced 8.91 of mean cuttings, which are significantly lower than those produced by W-configuration method and yet comparable to traditional method as presented in Table 1. This elucidated that the $\mathrm{W}$-configuration planting method can achieve more promising cuttings production rate as compared to $\mathrm{V}$-configuration and traditional planting methods.

In comparison to the study carried out by Bhuyan [16] in explicating proper multiplication methods for black pepper propagation, such as bamboo split and soil mound methods, the current finding elucidated that five-node cutting production from W-configuration method (11.97 cuttings per vine) is comparable to bamboo split method that is invented by Sri Lanka researcher with the mean value of 11.42 cuttings when converted the figures to five-node cutting. However, this method has several limitations, such as severe attack of termites on bamboos and the difficulty in maintenance, replacement and availability of suitable bamboos [17]. Meanwhile, soil mound method has higher pepper cuttings production per harvest, 
Table 1 Production of five-node cutting from three different cultivation methods.

\begin{tabular}{llllll}
\hline \multirow{2}{*}{ Cultivation method } & \multicolumn{5}{c}{ Number of five-node cutting/vine } \\
\cline { 2 - 6 } & $\mathrm{P}_{1}$ & $\mathrm{P}_{2}$ & $\mathrm{P}_{3}$ & $\mathrm{P}_{4}$ & Mean \\
\hline W-configuration & $12.04^{\mathrm{a}}$ & $12.17^{\mathrm{a}}$ & $12.38^{\mathrm{a}}$ & $11.29^{\mathrm{a}}$ & $11.97^{\mathrm{a}}$ \\
V-configuration & $10.21^{\mathrm{a}}$ & $10.29^{\mathrm{b}}$ & $8.46^{\mathrm{b}}$ & $6.67^{\mathrm{b}}$ & $8.91^{\mathrm{b}}$ \\
Traditional (control) & $9.75^{\mathrm{a}}$ & $6.83^{\mathrm{c}}$ & $6.71^{\mathrm{b}}$ & $4.71^{\mathrm{b}}$ & $7.00^{\mathrm{b}}$ \\
\hline
\end{tabular}

Means followed by the same superscript letter within a column are not significantly different at $p=0.05$ by DMRT.

$\mathrm{P}_{1}=1$ st round of pruning; $\mathrm{P}_{2}=2$ nd round of pruning; $\mathrm{P}_{3}=3$ rd round of pruning; $\mathrm{P}_{4}=4$ th round of pruning.

as well as per year as reported by Bhuyan et al. [16] and Khandekar et al. [17]. This method can produce mean cuttings of 14.39 if converted to five-node cuttings. The mean value is 2.42 higher than that compared to $\mathrm{W}$-configuration method. This could be attributed to the varying number of nodes produced by different types of multiplication methods. Soil mound method produced single node rooted cuttings. Whilst, in the current study, cuttings produced from W-configuration method are in line with the fulfillment of cuttings production criteria in Malaysia, for instant, the five-node cutting must have two plagiotropic branches on the two distal end nodes. Thus, the slightly lower performance of $\mathrm{W}$-configuration method over mound method is considered a trivial variation.

\subsection{Yield Study}

The yield assessment has been carried out for two harvesting seasons. The mean of green berry yield per vine for pepper planted on the three cultivation methods is significantly different throughout the two harvesting seasons as demonstrated at Table 2. Mature vine on $\mathrm{W}$-configuration (Fig. $2 \mathrm{~g}$ ) showed the highest mean green berry yield with $9.71 \mathrm{~kg} / \mathrm{vine} / \mathrm{year}$, followed by $7.43 \mathrm{~kg} /$ vine/year and $5.54 \mathrm{~kg} / \mathrm{vine} / \mathrm{year}$ for mature vine on V-configuration (Fig. 2f) and traditional cultivation method, respectively. Data collected so far had proven that W-configuration had better yield performance as compared to the V-configuration and out-yielded traditional planting method by $75.27 \%$ for the 1 st and 2 nd years of green berry production.

\subsection{ROI Analysis}

ROI analysis for the new farming concept is crucial to reveal feasibility of implementation. In this project, ROI comparison among three cultivation methods has been conducted. Based on ROI calculation (Table 3 ), the pepper cutting production plantation via implementation of $\mathrm{W}$-configuration cultivation method can achieve viable index of 0.35 , which was equivalent to $35 \%$ of return from over all of the investment cost. Via the implementation of W-configuration cultivation method, a pepper entrepreneur, which invested in a pepper cutting stock plant nursery with estimated cost of RM 213,081.00, can generate approximately RM $74,578.35$ of income in the 2 nd year of planting. In addition, the return would be much more lucrative for the subsequence cycle as the cost of belian support that has attributed to the greatest amount of investment cost for pepper plantation is reusable. This elucidated that the establishment cost for the subsequence planting cycle can be reduced up to $70 \%$. The profit can be increased dramatically up to $355 \%$ of the investment cost for the subsequence cycles of planting which excluded the cost of belian support.

V-configuration method was proved able to achieve viable index of 0.21 and 2.12 at the 1 st cycle and subsequent cycle of planting, respectively. Even though the investment is viable, the return index was proven to be lower as compared to $\mathrm{W}$-configuration and traditional planting for the 1 st planting cycle. This indicates that $\mathrm{V}$-configuration method is less profitable for investment. However, the ROI for the 
Table 2 Green berry yield performance of pepper planted on three different cultivation methods.

\begin{tabular}{llll}
\hline \multirow{2}{*}{ Cultivation method } & \multicolumn{3}{c}{ Green berry yield (kg/vine/year) } \\
\cline { 2 - 4 } & $\mathrm{HS}_{1}$ & $\mathrm{HS}_{2}$ & Mean \\
\hline W-configuration & $9.16^{\mathrm{a}}$ & $10.26^{\mathrm{a}}$ & $9.71^{\mathrm{a}}$ \\
V-configuration & $7.64^{\mathrm{b}}$ & $7.21^{\mathrm{b}}$ & $7.43^{\mathrm{b}}$ \\
Traditional (control) & $5.28^{\mathrm{c}}$ & $5.79^{\mathrm{c}}$ & $5.54^{\mathrm{c}}$ \\
\hline
\end{tabular}

Means followed by the same superscript letter within a column are not significantly different at $p=0.05$ by DMRT.

$\mathrm{HS}_{1}=1$ st harvesting season; $\mathrm{HS}_{2}=2$ nd harvesting season.

Table 3 ROI analysis for three cultivation methods.

\begin{tabular}{lll}
\hline \multirow{2}{*}{ Cultivation method } & \multicolumn{2}{c}{ ROI index (per ha) } \\
\cline { 2 - 3 } & 1st cycle (first two years) & 2nd and subsequent cycle \\
\hline W-configuration & 0.35 & 3.55 \\
V-configuration & 0.21 & 2.12 \\
Traditional (control) & 0.49 & 1.66 \\
\hline
\end{tabular}

Assumption: cost of investment per cycle (two years) for traditional planting = RM 213,081.00 [18].

Cost of investment per cycle (two years) after removal of belian support cost at subsequence planting cycle $=$ RM 63,081.00 [18] .

Price per cutting $=$ RM 3, price per belian support $=$ RM 25 .

subsequent cycle of planting is more promising compared to traditional planting.

Whilst, the ROI index on cutting production via traditional cultivation method is 0.49 for the 1 st cycle of planting. This proved that the cutting yield from this planting method was more viable for investment compared to $\mathrm{W}$-configuration planting method, even though the cutting yield via W-configuration is $41.52 \%$ greater than the traditional planting method. The additional cost of two belian posts for each planting point is the causal factor. For the subsequence planting cycle, the ROI can achieve index of 1.64, which means the investor can earn up to $164 \%$ from the total investment. However, this is still incomparable to ROI with index of 3.55 via the W-configuration planting method.

Overall, the analysis revealed that $\mathrm{W}$-configuration for production of cutting for commercialization purpose is most viable for investment among all planting methods. W-configuration, even though less viable compared to traditional planting method in the 1st cycle of planting, is able to upsurge the profit in subsequence cycle.

\section{Conclusions}

The invention of W-configuration cultivation method is anticipating in overcoming the planting materials shortage problem in Malaysia. At the same time, this project also aimed to evaluate the viability of establishing pepper farm, which was mainly for cuttings production purpose. The ROI analysis has proven the feasibility of $\mathrm{W}$-configuration method to create potential new income for pepper smallholders in Malaysia. Implementation of W-configuration cultivation method for the production of pepper cutting at stock nursery or plantation is a novelty in all of the pepper producing countries. This is a breakthrough in pepper industry, particularly in constraint of cutting production. This new farming concept will be disseminated to pepper farmer in Malaysia in years to come as an alternative way to generate income other than peppercorn production. In addition, W-configuration cultivation method is not limiting mass production of planting materials, but also aiming at the possibility of increasing yield per hectare in long run. The two cycles of yield assessment 
so far have proven the better yield performance of W-configuration method as compared to the traditional planting.

\section{Acknowledgments}

The authors would like to thank Mr. Liew Tet Chin for granting permission to conduct the experimental plot in the pepper farm under his tenure. Appreciation also goes to Mr. Melvin Alexander Anak Lanyeh, Mr. Wan Ambi and Mr. Sang Jam, research assistants of Malaysian Pepper Board for their excellent technical assistance in the field.

\section{References}

[1] Philip, V. J., Dominic, J., Triggs, G. S., and Dickinson, N. M. 1992. "Micropropagation of Black Pepper (Piper nigrum L.) through Shoot Tip Cultures." Plant Cell Report 12 (1): 41-4.

[2] Srinivasan, K. 2007. "Black Pepper and Its Pungent Principle-Piperine: A Review of Diverse Physiological Effects." Critical Reviews in Food Science and Nutrition 47 (8): 735-48.

[3] Paulus, A. D., Megir, G., and Eng, L. 2006. Pepper Technology Package. Sarawak: Department of Agriculture, 1-31.

[4] Ravindran, P. N., Nirmal, B. K., Sasikumar, B., and Krishnamurthy, K. S. 2000. "Botany and Crop Improvement of Black Pepper.” In Black Pepper: Piper nigrum, edited by Ravindran, P. N. Amsterdam, the Netherlands: Harwood Academic Publishers, 23-142.

[5] Sivaraman, K. 1987. "Rapid Multiplication of Quality Planting Material in Black Pepper." Indian Cocoa Arecanut Spices J. 11: 115-8.

[6] Thangaselvabal, T., Justin, C. G. L., and Leelamathi, M. 2008. "Black Pepper (Piper nigrum L.) 'The King of Spices': A Review.” Agri. Rev. 29 (2): 89-98.

[7] Sim, S. L., Paulus, A. D., and Eng, L. 2011. Manual for Production of Quality Planting Material of Pepper. Kuching, Malaysia: Malaysian Pepper Board, 1-57.

[8] Sim, S. L., and Rosmah, J. 2011. "Botany and Varietal Improvement." In Pepper Production Technology in Malaysia, edited by Sim, S. L., and Lai, K. F. Kuching,
Malaysia: Malaysian Pepper Board, 77-97.

[9] Gunaratne, W. D. L., Subasinghe, H. M. P. A., Yap, C. A., Anandaraj, M., and Manohara, D. 2015. Production of Quality Pepper (P. nigrum L.) Planting Materials. Jakarta, Indonesia: International Pepper Community, $1-15$.

[10] Sim, S. L., Paulus, A. D., and Eng, L. 2011. "Planting Material Production and Nursery Management." In Pepper Production Technology in Malaysia, edited by Sim, S. L., and Lai, K. F. Kuching, Malaysia: Malaysian Pepper Board, 77-97.

[11] Bavappa, K. V. A., and Gurusinghe, P. D. S. 1978. "Rapid Multiplication of Black Pepper for Commercial Planting." J. Plantation Crops 6: 92-5.

[12] Devasahayam, S., John, Z. T., Jayashree, E., Kandiannan, K., Prasath, D., Santhosh, J. E., Sasikumar, B., Srinivasan, V., and Suseela, B. R. 2015. Black Pepper-Extension Pamphlet, edited by Thomas, L., and Rajeev, P. Kozhikode, Kerala: ICAR-Indian Institute of Spices Research, 1-6.

[13] Paulus, A. D. 2011. "Planting and Maintenance." In Pepper Production Technology in Malaysia, edited by Sim, S. L., and Lai, K. F. Kuching, Malaysia: Malaysian Pepper Board, 102-5.

[14] George, C. K., Abdullah, A., and Chapman, K. 2005. Pepper Production Guide for Asia and the Pacific. Bangkok, Thailand: The International Pepper Community (IPC) and Food and Agricultural Organization of United Nations (FAO).

[15] Wahid, P., and Suparman, U. 1986. "Technical Method of Cultivation to Increase Pepper Productivity (ET)." Littro 2 (1): 1-11.

[16] Bhuyan, M. H. M. B., Rahman, S. M. L., and Sarker, J. C. 2015. "Explicating Proper Multiplication Method for Black Pepper Propagation in Bangladesh." Advance in Agriculture and Biology 4 (2): 75-8.

[17] Khandekar, R. G., Haldankar, P. M., Pande, V. S., Joshi, G. D., Bagade, D. S., Malve, D. B., Bhagwat, N. R., Rangwala, A. D., Jambhale, N. D., and Ramana, K. V. 2004. "Studies on Rapid Multiplication of Black Pepper (Piper nigrum L.) on Soil Mound.” Journal of Spices and Aromatic Crops 13 (1): 34-6.

[18] Malaysian Pepper Board. 2012. Annual Report of Division of Production \& Entrepreneurs Farmers Development. Malaysian Pepper Board. 